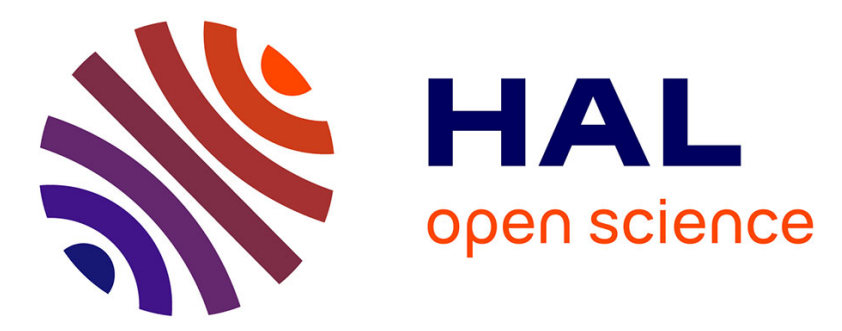

\title{
Experimental, analytical and numerical investigation to prevent the tow buckling defect during fabric forming
}

Mohamed Medhat Salem, Emmanuel de Luycker, Marina Fazzini, Pierre

\author{
Ouagne
}

\section{- To cite this version:}

Mohamed Medhat Salem, Emmanuel de Luycker, Marina Fazzini, Pierre Ouagne. Experimental, analytical and numerical investigation to prevent the tow buckling defect during fabric forming. Composites Part A: Applied Science and Manufacturing, 2019, 125, pp.105567. 10.1016/j.compositesa.2019.105567 . hal-02309890

\section{HAL Id: hal-02309890 https://hal.science/hal-02309890}

Submitted on 9 Oct 2019

HAL is a multi-disciplinary open access archive for the deposit and dissemination of scientific research documents, whether they are published or not. The documents may come from teaching and research institutions in France or abroad, or from public or private research centers.
L'archive ouverte pluridisciplinaire HAL, est destinée au dépôt et à la diffusion de documents scientifiques de niveau recherche, publiés ou non, émanant des établissements d'enseignement et de recherche français ou étrangers, des laboratoires publics ou privés. 


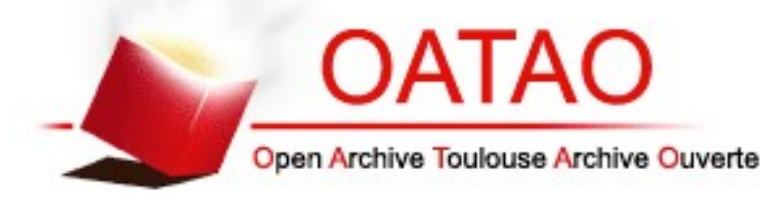

Open Archive Toulouse Archive Ouverte

OATAO is an open access repository that collects the work of Toulouse researchers and makes it freely available over the web where possible

This is an author's version published in: http://oatao.univ-toulouse.fr/24280

\section{Official URL:}

https://doi.org/10.1016/j.compositesa.2019.105567

\section{To cite this version:}

Salem, Mohamed Medhat and De Luycker, Emmanuel and Fazzini, Marina and Ouagne, Pierre Experimental, analytical and numerical investigation to prevent the tow buckling defect during fabric forming. (2019) Composites Part A: Applied Science and Manufacturing, 125. 1-13. ISSN 1359-835X

Any correspondence concerning this service should be sent to the repository administrator: tech-oatao@listes-diff.inp-toulouse.fr 


\title{
Experimental, analytical and numerical investigation to prevent the tow buckling defect during fabric forming ${ }^{\text {th }}$
}

\author{
M.M. Salem, E. De Luycker*, M. Fazzini, P. Ouagne \\ Laboratoire Génie de Production (LGP), Université de Toulouse, INP-ENIT, Tarbes, France
}

A R T I C L E I N F O

\section{Keywords:}

Fabrics/textiles (A)

Defect (B)

Mechanical testing (D)

Numerical analysis (C)

\begin{abstract}
A B S T R A C T
We investigate the causes, kinematic and possible ways to prevent the tow-buckling defect during the complex shape-forming of a dry woven reinforcement. Macro-scale compression leads to wrinkles; we focus on a mesoscale phenomenon generated by a non-uniform axial compression of the tow due to in-plane bending. An experimental study is presented, followed by an efficient method to predict the onset of the tow-buckling defect. This investigation is based on the combination of an experimentally validated analytical approach, with a macroscale simulation of the forming process for a single fabric layer. A particular focus is given to the resulting tow curvatures that allows us to predict the zones of high tow buckling probability. The relatively simple numerical approach based on Lagrange assumptions does not take into account tow slippage. However, for most cases, where buckles appear before slippage, this approach alleviates the compulsory need for an expensive meso-scale representation.
\end{abstract}

\section{Introduction}

Fiber reinforced structural composites offer great mechanical performances because of their low density compared to regular structural materials. Manufacturing such parts requires the use of a fibrous reinforcement. Among others, woven fabrics represent a large amount of the chosen reinforcement due to their high drapability, good permeability and good cohesion when subjected to multidirectional loading and high manufacturing processability [1]. However, defects that may jeopardize the mechanical integrity of the composites could appear, prior to resin injection, during the complex shape forming of woven reinforcements such as the resin transfer molding (RTM) process, as identified by Potter et al. [2].

Some of these defects, such as the preform wrinkling, have been extensively investigated in the literature. Several experimental investigations [3-5] and numerical investigations [6-8] led to the understanding of the mechanics behind the formation of the wrinkling defect and the ways to prevent it (blank holders design, ply orientations, etc.).

Other defects mentioned by Potter et al. [2] remain to be fully understood, such as, tow sliding/unweaving as experienced in $[4,9,10]$ and studied in $[11,12]$ or the tow buckling defect.

The tow buckling defect was defined by Ouagne et al. $[10,13]$ as a tow deflection out of the plane of the reinforcement by a few millimeters combined with a rotation around its axis. Capelle et al. [14] designed a special set of blank holders associated with a tetrahedral punch to limit the appearance of tow buckles. Tephany et al. [15] and Ouagne et al. [16] found from their preliminary study the causes that could lead and influence the tow buckles appearance. The said causes could be linked to the previously mentioned ways to prevent the wrinkling defect. A device was designed to recreate the conditions of the tow buckling defect and investigate the causes. They concluded, that the most influencing parameters are the in-plane bending of the tow, the reinforcement orientations and the applied loads in both warp and weft directions of the reinforcement. However, some other geometric and mechanical parameters were not investigated. Beakou [17] and Matveev [18] described a comparable phenomenon on carbon tape during the automatic layup process. They deducted that the lateral buckles are a result of the dissymmetrical in-plane longitudinal compression load generated in the tape via in-plane bending; they proposed an analytical solution to predict its appearance.

This work sets itself as a follow-up of Tephany's work [15] and a more in-depth investigation of the effects of tensile loads, nature and geometrical parameters of the tows on the tow buckling defect. Our aim is to better understand the defect appearance and the possibilities to prevent it. In conjunction with an experimental study, the analytical

\footnotetext{
* Corresponding author.

E-mail address: emmanuel.de-luycker@enit.fr (E. De Luycker).
} 
model proposed in $[17,18]$ was modified so that to predict the appearance of tow buckling in the woven fabric reinforcements. This paper is divided in two parts: the first one dealing with experimental investigation and the second one presenting the analytical modeling and the possibility to predict the tow buckling appearance during the forming of a complex shape, such as a prismatic shape, using an isogeometrical simulation. The aim of our numerical work is in the same vein as the work of Iwata et al. [19]; predicting defects appearance. The chosen numerical approach is much simpler though with the known limitations of macro-scale modeling which are unable to consider tow slippage contrary to meso-scale modeling. An isogeometrical framework is chosen for its capability to naturally evaluate the curvatures along the tows during a simulation. The main advantage here is the computational efficiency of the macro-scale description since no contact is computed within the fabric. Only contacts between the fabric and the tools are considered. It is therefore possible to perform such simulations on a laptop computer and it permits investigating a possible prediction of the tow buckling defect.

\section{Experimental study}

\subsection{Materials and experimental setup}

For this study, the same device (Fig. 1) as the one described in $[19,20]$ was used and modified. The device permits to impose different initial tensile loads in warp and weft directions of a woven fabric as represented in Fig. 1(a, c). The loads can therefore be applied in the fixed longitudinal tow network (direction 1, load 1) and in the transversal tows network submitted to in-plane bending (direction 2, load 2)

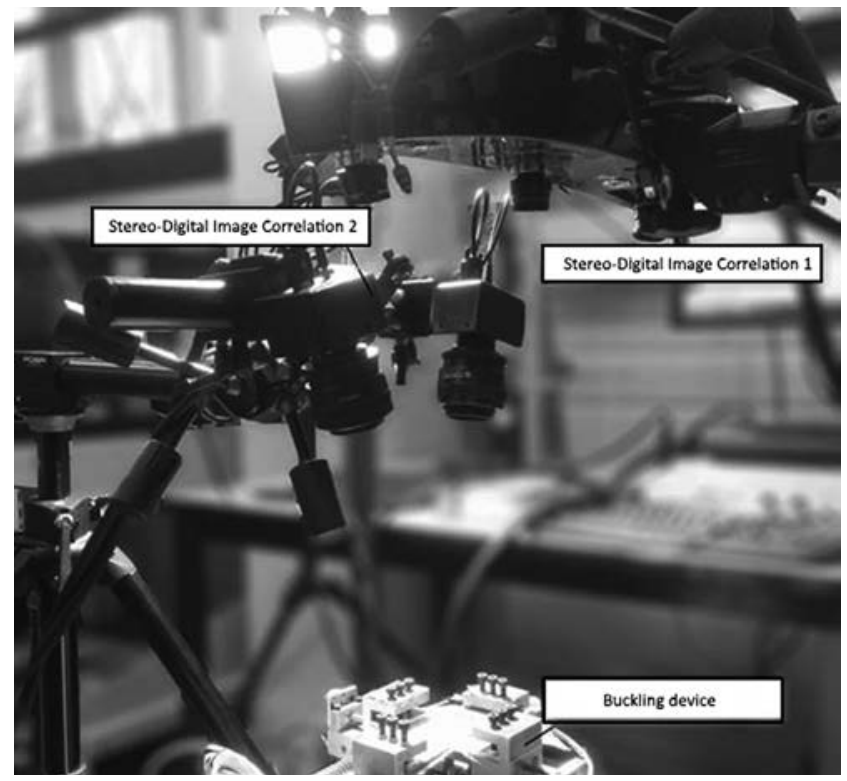

Fig. 2. S-DIC setups with the buckling device.

via each of the jaws bolts. The lateral jaws can then follow an in-plane circular translation motion as illustrated by Fig. 1(b, d).

In addition to the two load sensors that allow tension measurements, the device is instrumented with two Stereo Digital Image Correlation systems (S-DIC), as shown in Fig. 2, associated with the

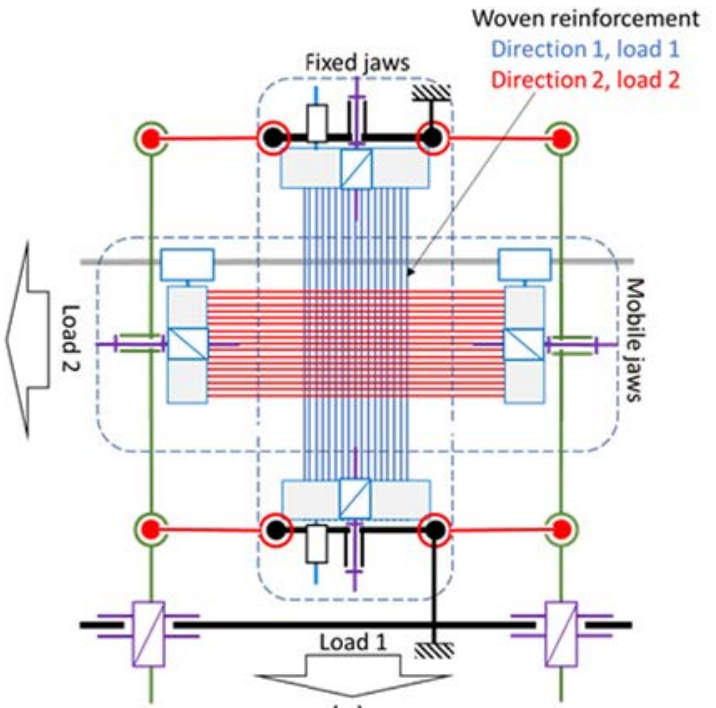

(a)

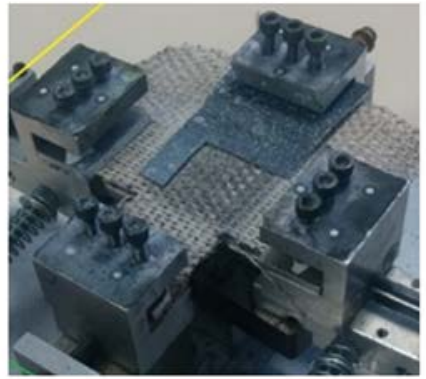

(c)

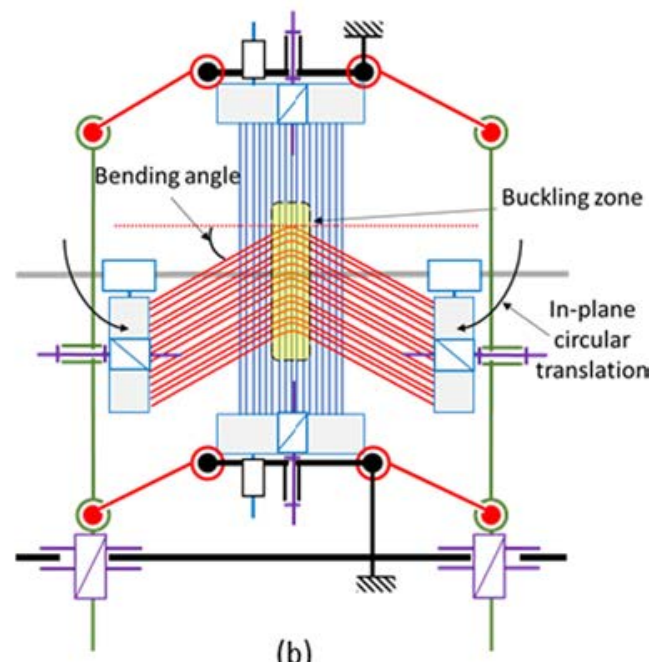

(b)

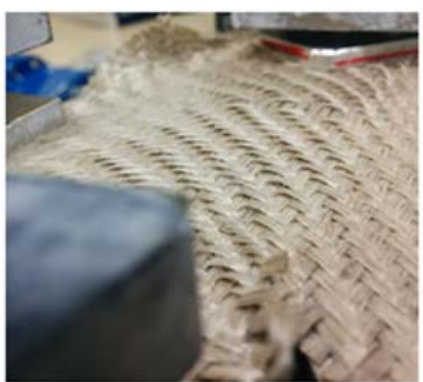

(d)

Fig. 1. Principle of the tow-buckling device: (a) kinematic diagram of the initial state of the device, (b) kinematic diagram of the bent state of the device, (c) picture of the device in the initial state, (d) picture of the buckles on the surface of the reinforcement. (For interpretation of the references to color in this figure legend, the reader is referred to the web version of this article.) 


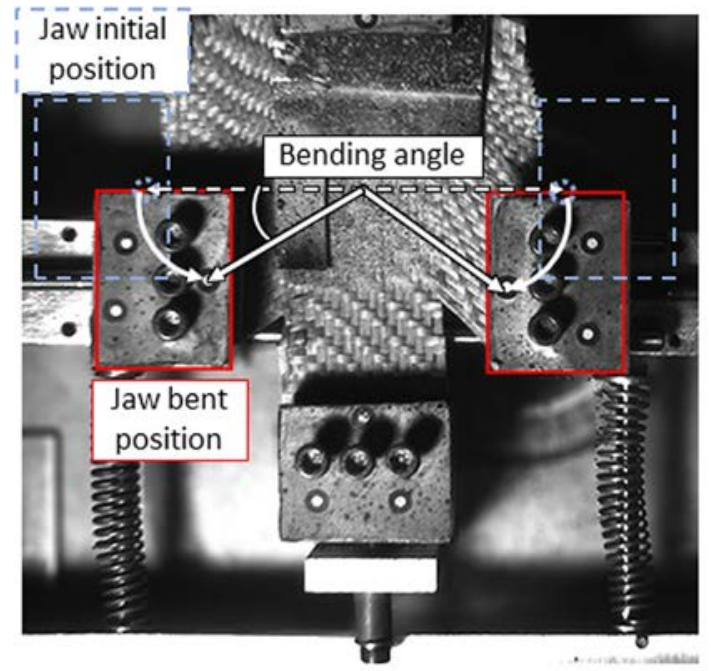

(a)

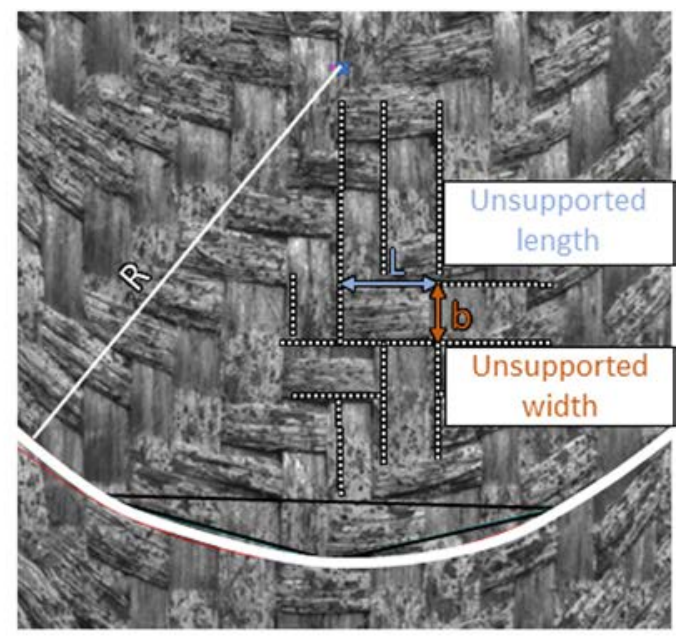

(b)

Fig. 3. (a) Bending angle measurement, (b) Tow's curvature radius measurement and representation of the unsupported length $\underline{L}$ and width $\underline{b}$ of the tow. (For interpretation of the references to color in this figure legend, the reader is referred to the web version of this article.)

software GOM ARAMIS ${ }^{\circledast}$. The first set of S-DIC set retrieves global information at the scale of the whole device (Fig. 3(a)) and the second one focuses on the formation of the tow buckles locally (Fig. 3(b)). The in-plane bending state of the reinforcement is evaluated in two ways. A global way via a so-called "bending angle of the device" defined in Tephany [15], as presented in Figs. 1(b) and 3(a), assuming that an originally straight tow rotates rigidly. A local way by extracting the curvature radius, using Image $\mathrm{J}^{\circledR}$ software, from the fabric images of Fig. 3(b).

In order to evaluate the buckling behavior of a tow within a fabric, at each bending state, its most deflecting profile is extracted from the 3D reconstructed upper surface of the fabric (Fig. 4(a)). The different states of the same profile are then compiled in Fig. 4(b). The red curve in Fig. 4(b) represents the final state of the profile of the buckled tow at a bending angle of $\sim 40^{\circ}$.

In order to determine the causes for the tow buckling defect, previously stated parameters such as tensile loading and bending angle were investigated more in depth alongside other fabric geometrical parameters such as the tow free dimensions and the tows nature. The tow free dimensions are the unsupported (free-floating) length and width of the apparent portion of the tow that is expected to buckle as illustrated in Fig. 3(b). Several reinforcements, with similar tow widths and/or unsupported lengths, were considered. Reinforcements such as flax fabrics, manufactured specially in the frame of a previous project by Groupe Depestele (France), and a carbon fabric (HexForce 48,600 U 1250) manufactured by Hexcel (France) and which characteristics are listed in Table 1.

\subsection{Experimental results}

\subsubsection{Effect of the tows dimensions and fabric construction}

To determine the effect of the tow geometrical properties, reinforcements manufactured with the same tows but different weaves were selected. This allows us to vary the tow unsupported length and width independently from other parameters. The selected reinforcements were made from desized-up flax tows and subjected to an initial load 1 of $300 \mathrm{~N}$ and a load 2 of $20 \mathrm{~N}$. Each reinforcement is bent in its plane up to a bending angle of $\sim 40^{\circ}$. From the experiments, the tow buckles height and tow rotation (Fig. 5) are extracted. The buckle height is calculated by subtracting the maximal height of the initial profile of the tow $\underline{H}_{0}{ }^{\max }$ from the maximal height of the deflected profile $\underline{H^{\max }}$. The tow rotation is calculated from the angle between the

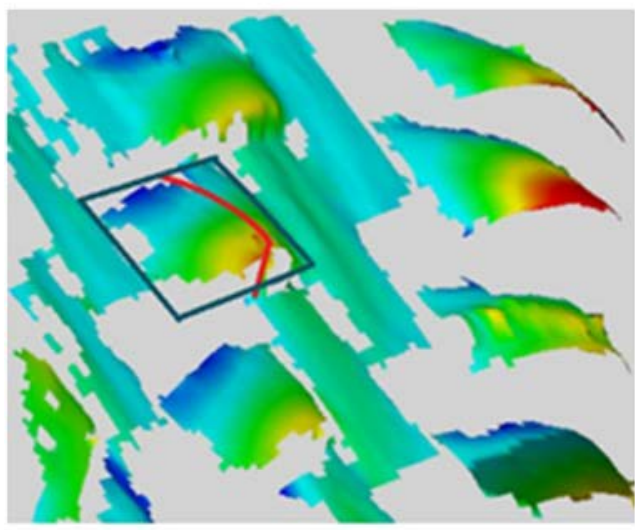

(a)

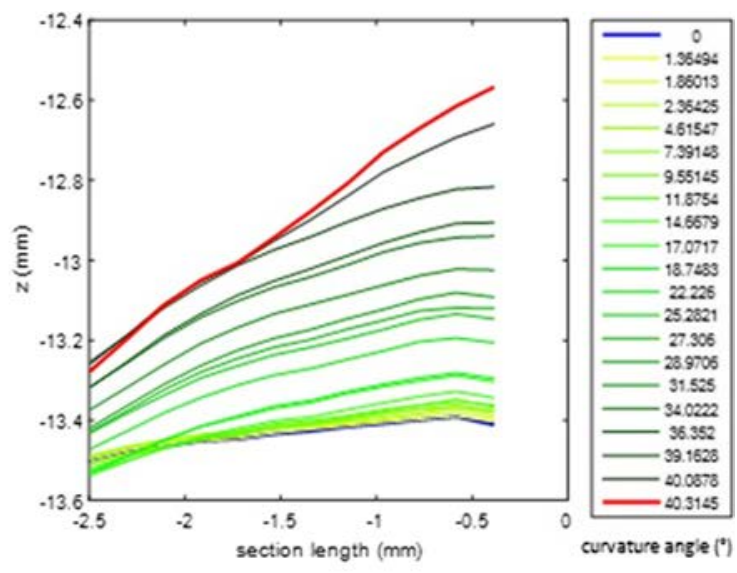

(b)

Fig. 4. (a) Reconstructed reinforcement surface by S-DIC (color corresponding to increasing height from blue to red), (b) Profile of a buckle for different bending angles. (For interpretation of the references to color in this figure legend, the reader is referred to the web version of this article.) 
Table 1

Characteristics of the different reinforcements used.

\begin{tabular}{|c|c|c|c|c|c|c|}
\hline Weave & Material & Surface density & Warp density & Weft density & Tow unsupported length (L) & Tow unsupported width (l) \\
\hline Twill $2 \times 2$ & Sized-up flax & $476 \mathrm{~g} / \mathrm{m}^{2}$ & $380 / \mathrm{m}$ & $385 / \mathrm{m}$ & $6.1 \mathrm{~mm}$ & $2.5 \mathrm{~mm}$ \\
\hline Twill $2 \times 2$ & Desized-up flax & $465 \mathrm{~g} / \mathrm{m}^{2}$ & $380 / \mathrm{m}$ & $430 / \mathrm{m}$ & $5.7 \mathrm{~mm}$ & $2.4 \mathrm{~mm}$ \\
\hline Twill $2 \times 2$ & Carbon fiber & $600 \mathrm{~g} / \mathrm{m}^{2}$ & $380 / \mathrm{m}$ & $380 / \mathrm{m}$ & $6.4 \mathrm{~mm}$ & $2.6 \mathrm{~mm}$ \\
\hline Plain (A) & Desized-up flax & $262 \mathrm{~g} / \mathrm{m}^{2}$ & $380 / \mathrm{m}$ & $210 / \mathrm{m}$ & $6.5 \mathrm{~mm}$ & $2.1 \mathrm{~mm}$ \\
\hline Plain (B) & Desized-up flax & $517 \mathrm{~g} / \mathrm{m}^{2}$ & $190 / \mathrm{m}$ & $195 / \mathrm{m}$ & $5.4 \mathrm{~mm}$ & $4.5 \mathrm{~mm}$ \\
\hline Plain (C) & Desized-up flax & $458 \mathrm{~g} / \mathrm{m}^{2}$ & $380 / \mathrm{m}$ & $385 / \mathrm{m}$ & $2.8 \mathrm{~mm}$ & $2.6 \mathrm{~mm}$ \\
\hline
\end{tabular}

chord of the initial profile and the chord of the buckled profile. The influence of the unsupported dimensions on the tow buckles height and tow rotation during buckling is presented in Fig. 6(a, b).

Fig. 6(a) shows that the maximal height and rotation of the tows increase together with the unsupported length. This is explained by the increase in the mobility of the buckling tow allowing it more room to rise and rotate. It causes a higher perceivable buckle. Fig. 6(b) shows that the increase of tow width still increases the maximal registered height whereas the rotation level decreases. Each of the transversal buckling tow is supported underneath it by a longitudinal fixed tow. As the tow buckles upward, it does so by combining two motions, i.e., deflection and rotation. During the early rotation stages of the buckle, the inner edge lifts and the outer edge has a tendency to sink until the whole tow is fully deflected. The narrower the tow, the faster the whole tow lifts completely from the supporting tow for lower bending angles. Fig. 6(a, b) also show that a higher bending angle is required to fully lift a larger buckling tow from its supporting tow. For the same final bending angle, wider tows have less rotation with a slight increase in height $(60 \%$ rotation angle loss against $6 \%$ height increase for a $42 \%$ larger tow) as illustrated in Fig. 7. Consequently, the tow buckles look smaller.

\subsubsection{Effect of the tow type}

In order to study the effect of tow type on the buckling, three different reinforcements manufactured from three different tows but with similar woven structures were chosen so that to keep similar dimensions, i.e. sized-up flax, desized-up flax and carbon fiber all in $2 \times 2$ twill weaves. Each tow of the studied fabrics have different tensile, bending and torsional rigidities that are expected to influence the buckling mechanism. However it is difficult to experimentally decouple each of those rigidities. Consequently, we studied the tow type as a whole. The properties of the tows are presented in Table 2 with the methods used to obtain them explained in the parameters identification Section 3.2.

During the tests, each reinforcement is loaded in tension with $300 \mathrm{~N}$ in load 1 and $20 \mathrm{~N}$ in load 2. This load is spread over 20 tows. Each reinforcement is bent in-plane up to an angle of $\sim 40^{\circ}$. The tow maximal height and the tow rotation are represented respectively in Fig. 8(a) and (b). Fig. 8(a) shows that the buckles elevation is higher for the carbon tows than the other considered tows. The elevation of the buckle also begins from lower in-plane bending angles $\left(\sim 8^{\circ}\right)$. One can also see that the sized-up flax tows exhibit higher maximal tow elevation than the desized-up ones.

A direct correlation between the increase of tow rigidities and the buckle elevation is observed. It is also possible to observe that for the three reinforcements considered, the appearance of the tow buckles happens for lower in-plane bending angles when the tow rigidities increases.

Fig. 8(b) also shows that the rotation of the buckle happens from low in-plane bending angle and the tow rotation angle is much larger for the most rigid carbon tows than the two flax tows. In the case of the two flax tows, the tow rotation angle evolution is similar which is probably due to the relatively low difference in their rigidities. This correlates well with the observation of the maximum elevation of the tow buckle.

2.2.3. Effect of the tows tension in direction 1: fixed tow network (load 1)

To study the effect of load 1 on the buckles, a series of tests has been conducted on 5 samples of $2 \times 2$ twill weave fabrics manufactured from sized-up flax and carbon tows respectively while imposing each time an initial load in direction 1 between $20 \mathrm{~N}$ and $400 \mathrm{~N}$ spread over 20 tows. The load in direction 2 is initially $20 \mathrm{~N}$. Each sample is bent in-plane up to an angle of $\sim 40^{\circ}$. The results of the test series are given in Fig. 9(a) for the sized-up flax fabric and (b) for the carbon reinforcement.

As shown in both Fig. 9(a) and (b), the maximal height reached by the tow evolves oppositely to the curvature radius of the tow. The lower the final curvature radius (increase in the tow curvature) and the higher the tow buckles. The final rotation angle, on the other hand seems to be fairly constant and independent of the final curvature radius. When considering the evolution of both elevation and tow rotation, Fig. 10 gives an idea on the kinematics involved during the bucking. On early bending stages, the height is mainly due to the rotation of the tow; then, as the tow continue to bend in its plane, the rotation seems to stabilize while the elevation further increases. This in turns suggests that the elevation at this point is mainly due to a global deflection of the tow that can be seen in the different tows final profiles in Fig. 11. The reason behind the parabolic trend of the curvature radius (Fig. 9(a, b)) can be attributed to the combination of the in-plane bending imposed by the

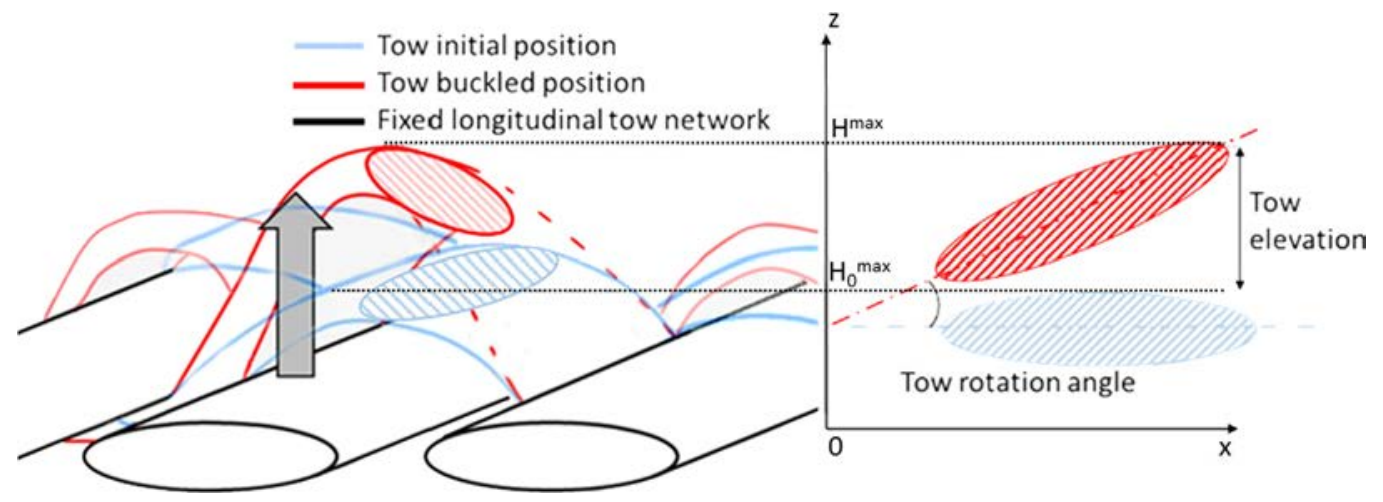

Fig. 5. Tow buckling illustration. (For interpretation of the references to color in this figure legend, the reader is referred to the web version of this article.) 

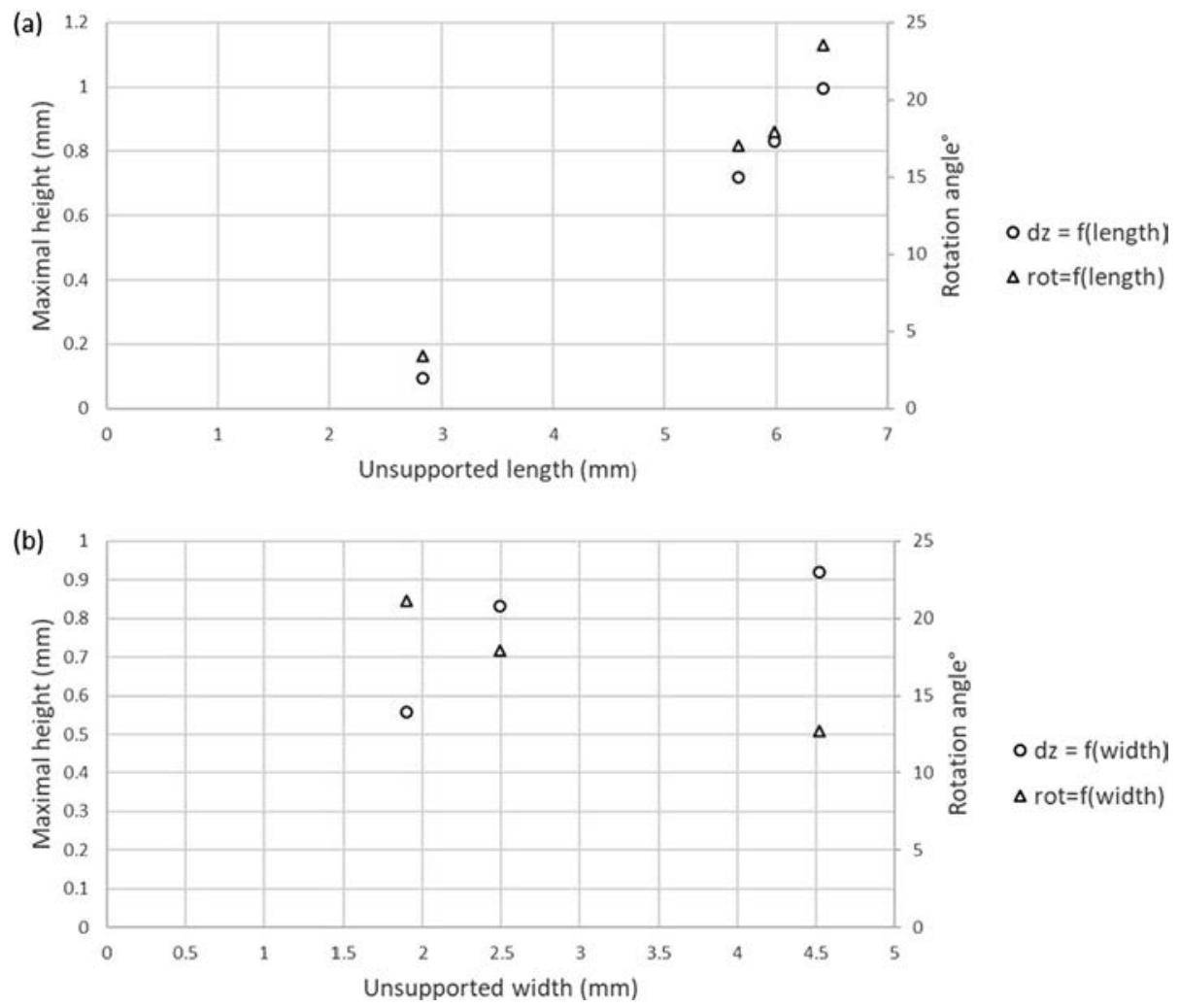

Fig. 6. Evolution of the maximal height and the rotation of the buckling tow as a function of the (a) unsupported length, (b) unsupported width.

jaws alongside the tow sliding (up to $2.81 \mathrm{~mm}$ ) as represented in Fig. 12.

During the applied in-plane bending on the device, tow sliding may take place as shown in Fig. 12 and this phenomenon may have consequences on the final curvature. The tow sliding as explained by Labanieh et al. [16] depends on the contact pressure between the warp and the weft tows. As the load 1 increases, the tow sliding is inhibited going from $2.8 \mathrm{~mm}$ at a load 1 of $20 \mathrm{~N}$ to $1.1 \mathrm{~mm}$ at a load 1 of $400 \mathrm{~N}$ for the sized-up flax. This explains the three stages presented in Fig. 9(a, b), which are described further below:

- For load 1 from $20 \mathrm{~N}$ to $200 \mathrm{~N}$ : a low pressure is applied on the perpendicular tows cross-points. This allows the tows expected to buckle to slide, preventing them from achieving their potential full curvature.

- At $\sim 200 \mathrm{~N}$ : an optimum is reached. The in-plane bending and tow sliding leads to the maximal possible curvature of the tows submitted to in-plane bending.

- Above $200 \mathrm{~N}$ : the pressure applied on the cross-points combined with the friction phenomenon prevent the tow from sliding and from curving leading to a decreased curvature compared to the optimum.
Table 2

Tows dimensional and mechanical properties with analytical and experimental critical buckling radii.

\begin{tabular}{llllll}
\hline Tow origin & $\begin{array}{l}\text { Twill } \\
2 \times 2 \\
\text { sized up } \\
\text { flax }\end{array}$ & $\begin{array}{l}\text { Twill } \\
2 \times 2 \\
\text { desized } \\
\text { up flax }\end{array}$ & $\begin{array}{l}\text { Twill } \\
2 \times 2 \\
\text { carbon } \\
\text { fiber }\end{array}$ & $\begin{array}{l}\text { Plain A } \\
\text { desized } \\
\text { up flax }\end{array}$ & $\begin{array}{l}\text { Plain C } \\
\text { desized } \\
\text { up flax }\end{array}$ \\
\hline $\begin{array}{l}\text { Linear density (g/ } \\
\text { m) }\end{array}$ & 0.614 & 0.494 & 0.813 & 0.488 & 0.478 \\
E1 (N/mm $)$ & & & & & \\
L (mm) & 19,800 & 7900 & 132,700 & 7820 & 7645 \\
b (mm) & 6.11 & 5.66 & 6.42 & 6.46 & 2.83 \\
h (mm) & 2.48 & 2.40 & 2.6 & 2.10 & 2.65 \\
$\alpha \quad$ & 0.4 & 0.4 & 0.38 & 0.4 & 0.4 \\
m & 2 & 2 & 2 & 2 & 2 \\
D11 (N.mm) & 1 & 1 & 1 & 1 & 1 \\
D66 (N.mm) & 1.18 & 0.72 & 7.55 & 0.72 & 0.63 \\
Rcr analytical (mm) & 0.44 & 0.17 & - & 0.17 & 0.17 \\
Rcr experimental & 2082.9 & 1482.2 & - & 1275.7 & 717.7 \\
$\quad(m m)$ & 2255 & 1627 & - & 1390 & 803 \\
$\Delta(\%)$ & 7.63 & 8.90 & - & 8.22 & 10.62 \\
\hline
\end{tabular}

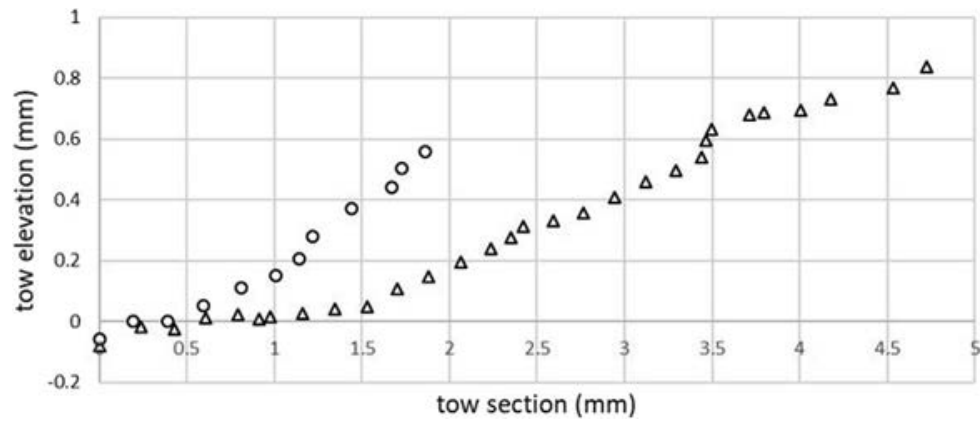

$\Delta$ width $4.52 \mathrm{~mm}$

o width $2.1 \mathrm{~mm}$

Fig. 7. Final profile of buckled tows with different unsupported widths for a bending angle of $40^{\circ}$. 


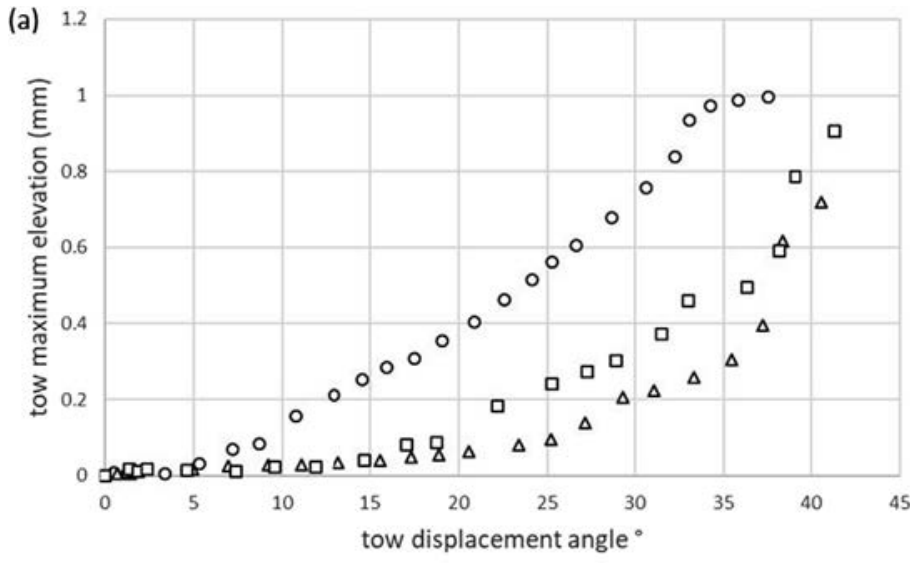

- carbon fiber twill $2 \times 2$

$\Delta$ desized flax twill $2 \times 2$

口 sized up flax twill $2 \times 2$

(b)

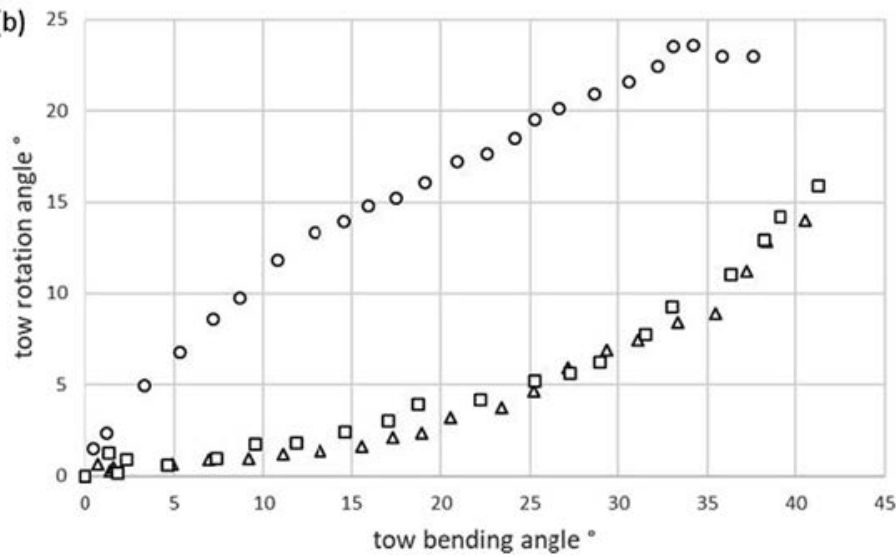

o carbon fiber twill $2 \times 2$

$\Delta$ desized flax twill $2 \times 2$

$\square$ sized up flax twill $2 \times 2$

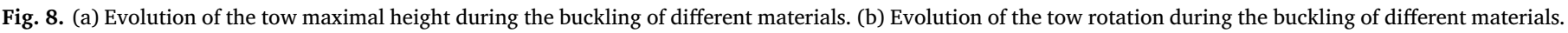

When considering the influence of the increasing load 1 on the tow buckling within the flax and carbon-based fabrics, similar behavior was observed. It indicates that keeping low loads in direction 1 may delay the appearance of the buckles and reduce their height since tow sliding taking place (in a limited extent without the appearance of gaps). This sliding tend to reduce the curvature of the tow submitted to in-plane bending. These results confirm that a reduction of the blank-holder pressure as performed by Capelle et al. [18] on the tows perpendicular to the ones exhibiting the defect permits to delay the appearance of the buckles. On the other hand, when the load in direction 1 is larger than $200 \mathrm{~N}$ for both the fabrics, the high contact pressures prevent the tow sliding but also limits the in-plane bending of the tows. Rising the load in direction 1 to high tension values may therefore limit the curvature and consequently delay the appearance and reduce the height of the buckles. However, a risk of gaps due to tow sliding may happen, and such approach may be considered with a great care.

2.2.4. Effect of the tows tension in direction 2: tow network submitted to inplane bending (load 2)

As for load 1, the study was done on sized-up flax with only the initial load 2 as a variable for each of the samples going from $20 \mathrm{~N}$ to $400 \mathrm{~N}$. The results are summarized in Fig. 13.

As observed with load 1, the maximal height registered evolves oppositely to the curvature radius of the tow while the rotation angle is similar for all loads. The decrease of the curvature is explained by an increase in load 2 that adds more slide to the tows and prevents them from curving or buckling. Increasing the load in direction 2 should therefore favor a reduction of the buckles size.

\section{Analytical analysis}

In order to be able to predict the buckling onset during the forming of a woven structure, an analytical model is set up. This approach was previously used in the literature by Beakou et al. [17] and Matveev et al. [18] in order to address the problem of tape buckling during the automated fiber placement following a curved path. The following work is inspired by their analytical framework.

\subsection{Analytical model}

Fibrous materials exhibit complex behavior; due to the possibility for fibers to slide; cross sections during bending do not necessarily remains perpendicular to the neutral fiber. The Kirchhoff-Love plate theory (and corresponding Euler-Bernoulli beam theory) are most of the time not representing well the behavior of fabrics, interlocks, and virgin fiber bundles. The bending rigidity doesn't relate to the tension one. This is illustrated by the difference of bending behavior between a phone book with the pages glued together (tension/compression is generated) and without glue (bending of each page taken separately plus friction). In this part of the work, fibers inside a flat tow, in small strain (only the onset of buckling is considered) possess cohesion, due to the entanglement of fibers and due to sizing (for desized-up flax, we assume that a small amount of sizing remains). With this assumption, we consider that fibers don't slide inside a tow and that Kirchhoff plate theory is valid; a link can then be made between the kinematic (the curvature) and the load (axial compression P) as illustrated Fig. 14.

If the tow is considered as a thin homogenous orthotropic plate $[17,18]$, simply supported at its outer edges and clamped on its radial edges by the neighboring tows, the differential equation for plate bending, in Eq. (1), can be solved by using the Rayleigh-Ritz approach 

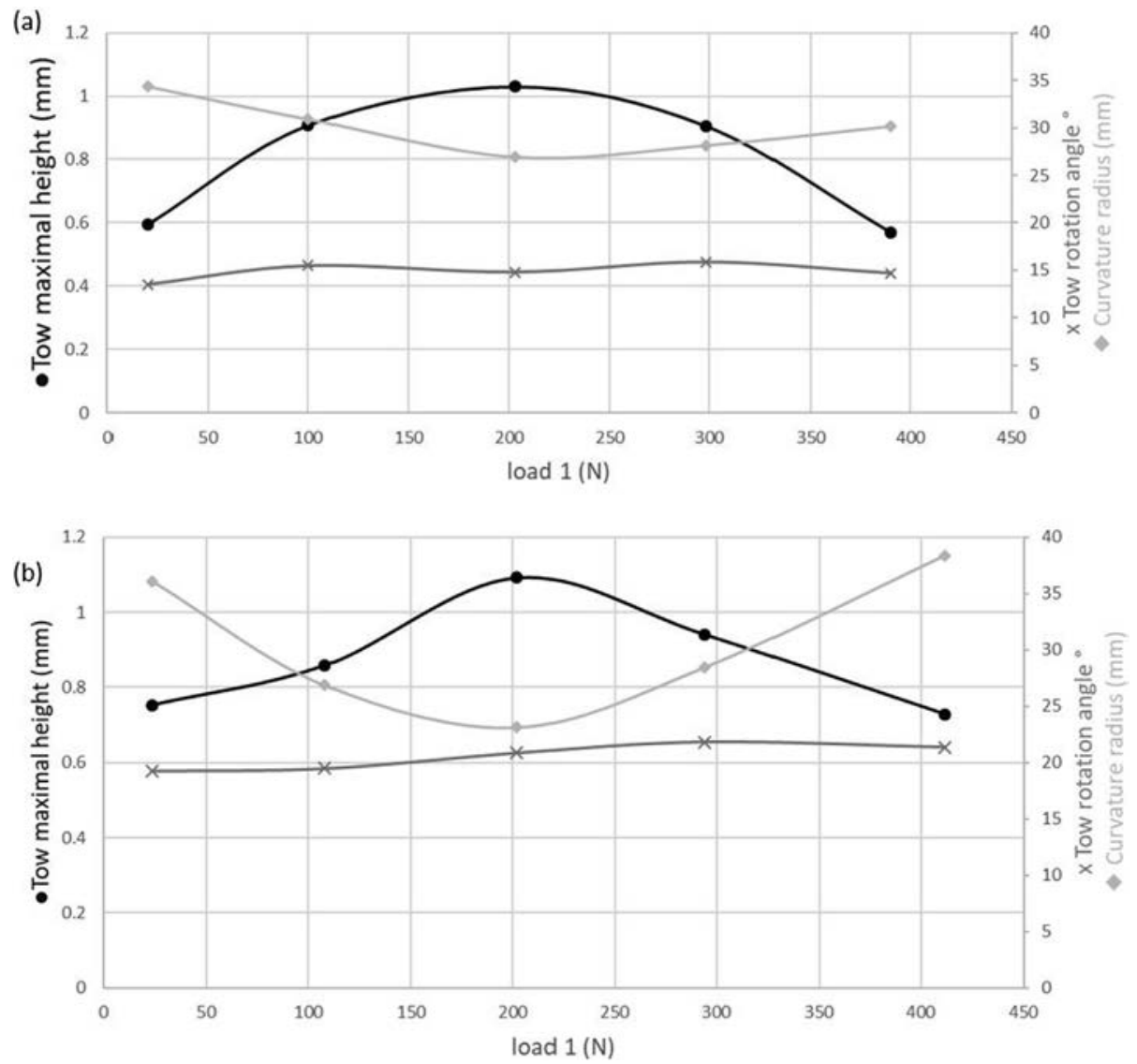

Fig. 9. Evolution of the tow maximal height, rotation and curvature radius during the buckling of (a) sized-up flax tows within the fabric as a function of load 1. (b) Carbon fiber tows within the fabric as a function of load 1.

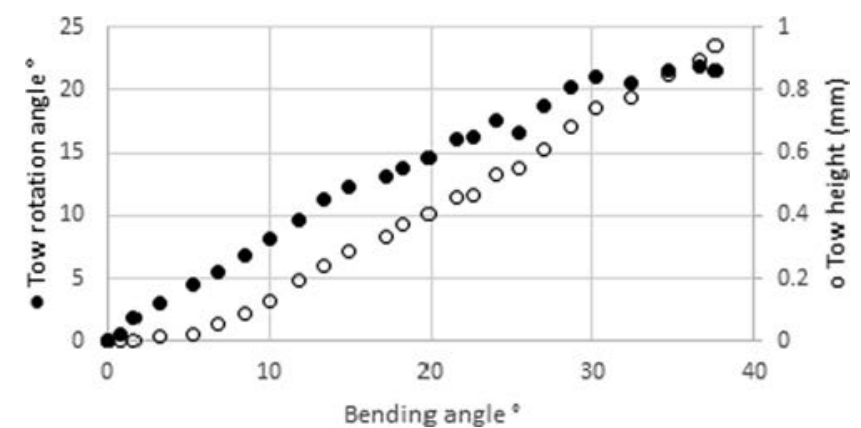

Fig. 10. Evolution of tow height and tow rotation as a function of the in-plane bending angle for a sized-up flax tow under load 1 of $100 \mathrm{~N}$ and load 2 of $20 \mathrm{~N}$.

[20]:

$\nabla^{2} w=P$

where $\underline{w}$ is the plate deflection, which, alongside its first derivative $\underline{w}$, are null on the clamped edges of the tow, represented in Fig. 15, ( $\underline{w}$ $(\underline{x}=0)=\underline{w}(\underline{x}=L)=0$ and $\left.\underline{w}^{\prime}(\underline{x}=0)=\underline{w}^{\prime}(\underline{x}=\underline{L})=0\right)$. The outer edge is supposed to be simply supported and only its deflection $\underline{w}$ is null $(\underline{w}(y=0)=0)$. Under those assumptions, the deflection $\underline{w}$ can be described as a linear combination of the $\underline{n}^{\text {th }}$ first modes and approximated, in Eq. (2), based on the boundary conditions and the compressive load formulated previously in Eq. (1). A closed-form solution in a RayleighRitz approach can be considered:

$w(x, y)=\sum_{i=1}^{n} c_{i}\left(1-\frac{y}{b}\right)^{i+1}\left(1-\cos \left(\frac{2 \pi m x}{L}\right)\right)$

where $\underline{m}$ is the buckling mode. Only the first one $(\underline{m}=1)$ will be taken into account because it corresponds to the most critical buckling mode. $\underline{P}$ the compressive load, caused by the in-plane bending of the tow is given by Eq. (3):

$P(y)=P_{0}\left(1-\frac{\alpha y}{b}\right)$

where $\underline{P}_{0}$ is the minimal buckling load applied at the inner edge, as represented in Fig. 14, of the bent plate and $\underline{\alpha}$ is the load non-uniformity coefficient also represented in Fig. 14. The Rayleigh-Ritz approach dictates that the total energy $\underline{\Pi}$, represented in Eq. (4), should be minimized by differentiating it with respect to the deflection's amplitude, $\underline{c}_{i}$, as shown in Eq. (5):

$\Pi(w)=U(w)-Q(w)$

$\frac{d \Pi}{d c_{i}}=0$

where $\underline{U(w)}$ is the elastic strain energy of the plate which is defined in Eq. (6) and $Q(w)$ is the work of the compressive load as defined in Eq. (7):

$$
\begin{aligned}
U(w)= & \frac{1}{2} \int_{0}^{L} \int_{0}^{b}\left(\mathrm{D} 11\left(\frac{d^{2} w}{d x^{2}}\right)^{2}+\mathrm{D} 22\left(\frac{d^{2} w}{d y^{2}}\right)^{2}+2 \mathrm{D} 12\left(\frac{d^{2} w}{d x^{2}}\right)\left(\frac{d^{2} w}{d y^{2}}\right)\right. \\
& \left.+4 \mathrm{D} 66\left(\frac{d^{2} w}{d x d y}\right)^{2}\right) d y d x
\end{aligned}
$$

$\mathrm{Q}(\mathrm{w})=\frac{1}{2} \mathrm{P}_{0} \int_{0}^{L} \int_{0}^{b}\left(1-\frac{\alpha y}{b}\right)\left(\frac{d^{2} w}{d x^{2}}\right)^{2} d y d x$

where $\underline{L}$ is the length of the plate, $\underline{b}$ the width of the plate and $\underline{D x x}$ are the bending stiffness of the plate. Replacing $\underline{w}$ for $(\underline{n}=1)$ and in Eqs. 


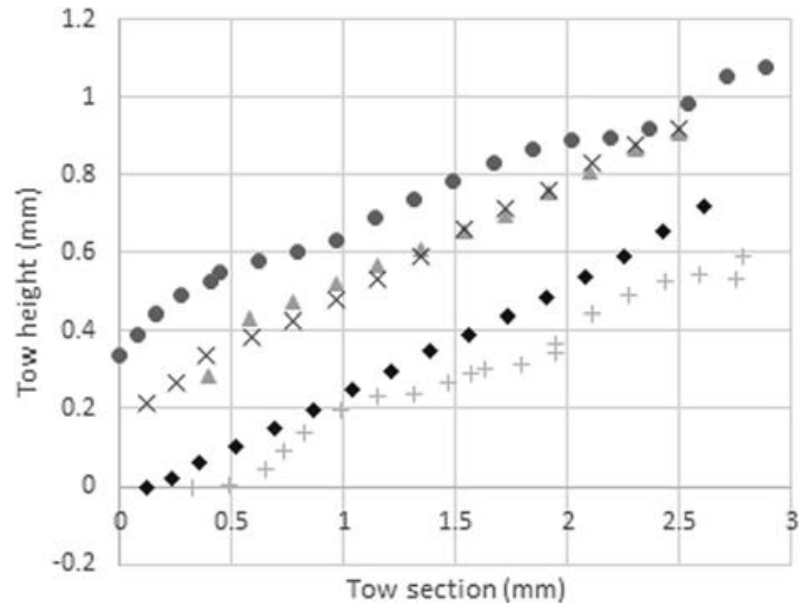

+test 1: load $120 \mathrm{~N} \operatorname{load} 220 \mathrm{~N}$

$\Delta$ test 2: load $1100 \mathrm{~N}$ load $220 \mathrm{~N}$

- test 3: load $1200 \mathrm{~N}$ load 2 20N

$\times$ test 4: load $1300 \mathrm{~N}$ load $220 \mathrm{~N}$

- test 5: load $1400 \mathrm{~N}$ load $220 \mathrm{~N}$

Fig. 11. Final sized up flax tow profiles under an in-plane bending angle of $\sim 40^{\circ}$.

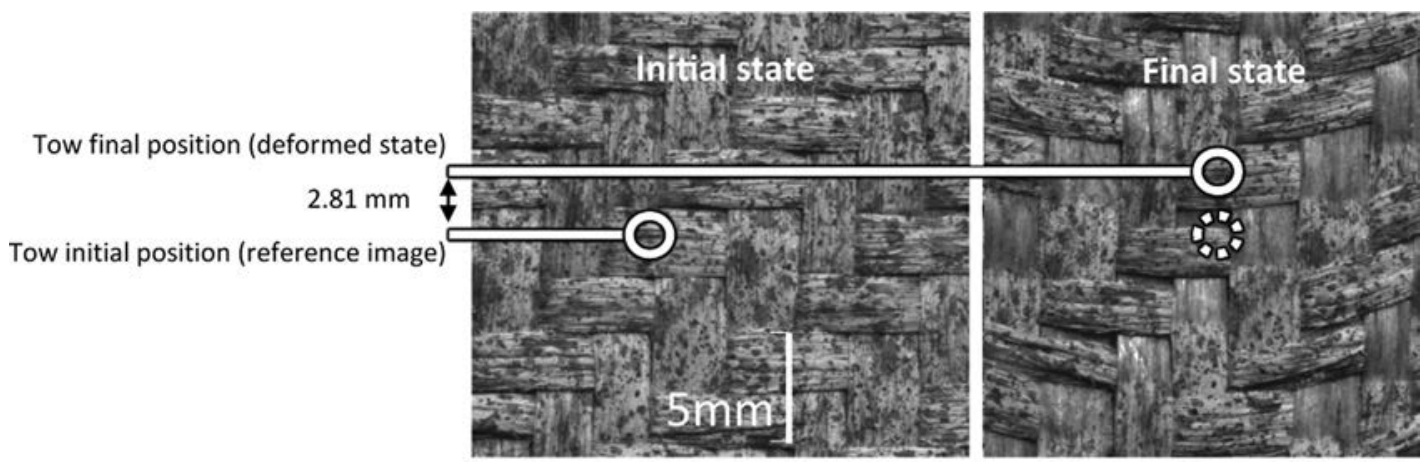

Fig. 12. Tow Sliding during the tow in-plane bending.

(2), (6) and (7) and then minimizing $\underline{\Pi}$ with respect to $\underline{c_{1}}$, the critical buckling compressive load, $\underline{P c r}$ is obtained as given by Eq. (8):

$P c r=\frac{1}{6-\alpha}\left(\frac{24 D 11 m^{2} \pi^{2}}{L^{2}}+\frac{90 D 22 L^{2}}{b^{4} m^{2} \pi^{2}}+\frac{160 D 66}{b^{2}}-\frac{40 D 12}{b^{2}}\right)$

During bending, taking into consideration small deformations and the intra-tow cohesion of fibers, the edge of the tow is assumed to bend following the curvature of a radius $\underline{R}$ at an angle $\underline{\theta}$ according to Kirchhoff's plate theory, represented in Fig. 14. The length of the inner side of the tow caused by the bending is found to be equal to $\theta(R-b / \alpha)$ and the deformation of the tow is equal to $b /(\alpha R)$. The load in the inner edge, $\underline{P}_{0}$, generated by in-plane bending of the tow can be written $[21,22]$ as:
$P_{0}=\frac{E 1 h b}{\alpha R}$

In the case where the minimal $\underline{P c r}$ (that is calculated for a reinforcement values of $\underline{L}$ : tow unsupported length, $\underline{h}$ : tow thickness and $\underline{b}$ : unsupported tow width) is equal to $\underline{P_{0}}$, we are able to connect the critical load to the geometrical bending parameters of the tow and in particular to find the critical buckling radius $\underline{\operatorname{Rcr}}$ as:

$R c r=\frac{E 1(6-\alpha) b h}{\alpha\left(\frac{24 D 11 m^{2} \pi^{2}}{L^{2}}+\frac{90 D 22 L^{2}}{b^{4} m^{2} \pi^{2}}+\frac{160 D 66}{b^{2}}-\frac{40 D 12}{b^{2}}\right)}$

Assimilating the tow to a thin orthotropic plate means that the bending $(\underline{D 11}, D 22)$, shear $(\underline{D 12, D 21})$ and torsional $(\underline{D 66})$ stiffnesses

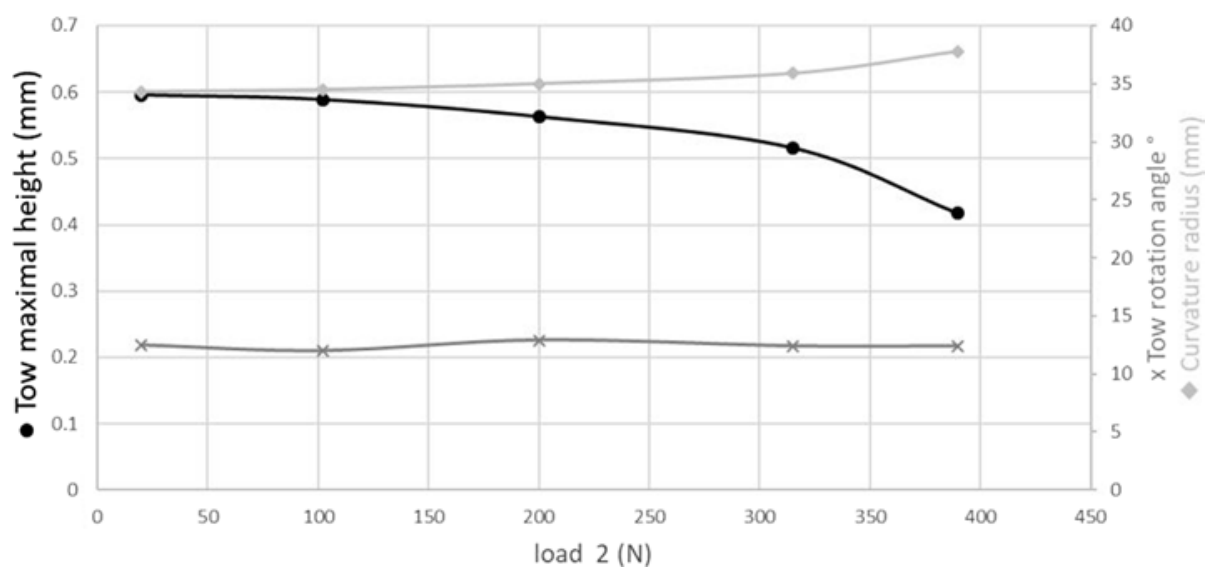

Fig. 13. Evolution of the tow maximal height, rotation and curvature radius during the buckling of sized-up flax as a function of load 2 . 


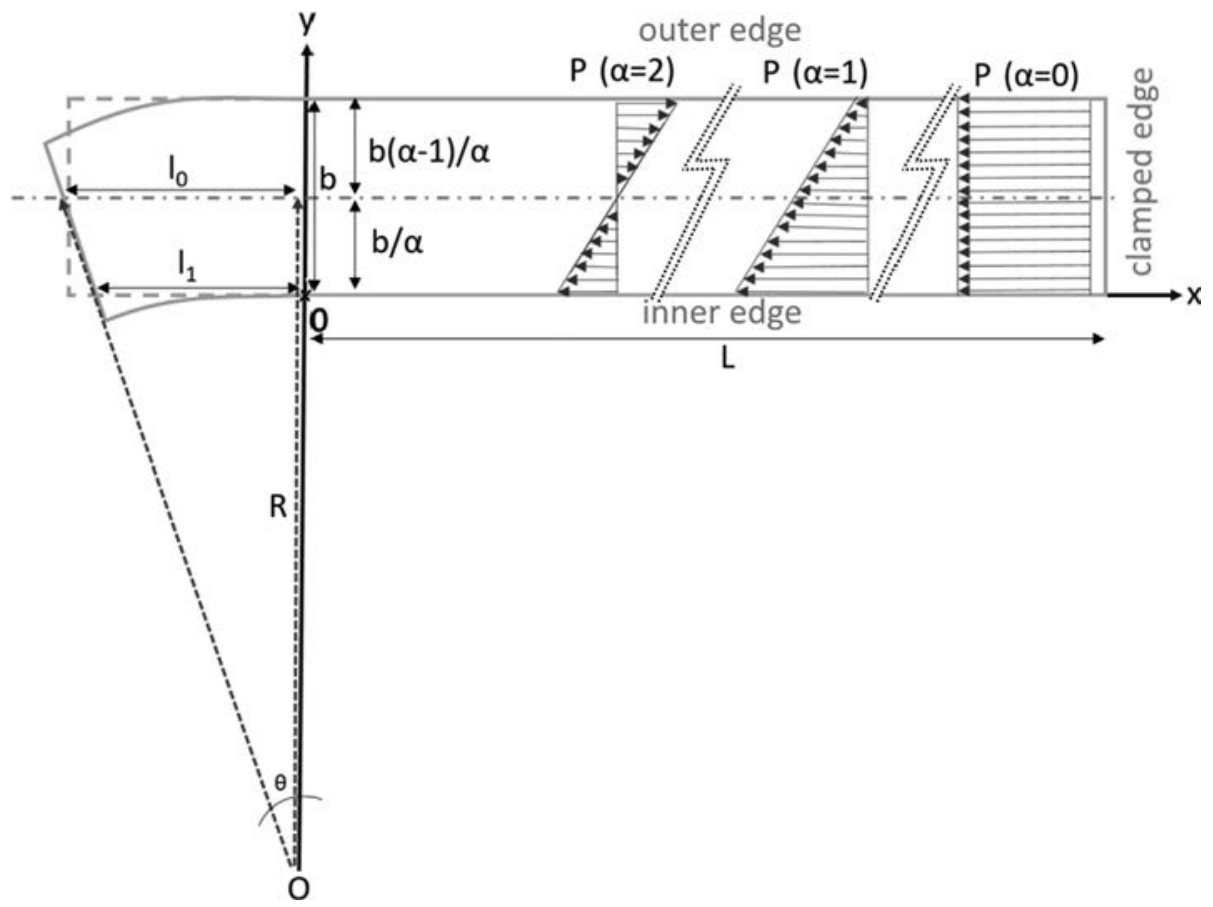

Fig. 14. Tow representation as an orthotropic plate with compressive load P representation for different values of the non-uniformity coefficient $\alpha$.

that can be recovered from the laminate plate theory, where, the bending stiffness matrix for a single layer $[21,22]$ is:

$\left\{\begin{array}{l}M_{x} \\ M_{y} \\ M_{z}\end{array}\right\}=\left[\begin{array}{ccc}D 11 & D 12 & 0 \\ D 21 & D 22 & 0 \\ 0 & 0 & D 66\end{array}\right]\left\{\begin{array}{l}k_{x} \\ k_{y} \\ k_{z}\end{array}\right\}$

where $\underline{D 11}$ and $\underline{D 22}$ are respectively the bending stiffness in the longitudinal and transversal directions, representing the required torque ( $\underline{M}_{x}$ in longitudinal and $\underline{M}_{y}$ in transversal direction) necessary to generate a unit curvature $\left(\underline{K}_{x}\right.$ and $\left.\underline{K_{y}}\right) . \underline{D 11}$ and $\underline{D 22}$ can therefore be considered as the flexural rigidity $\left(\underline{B}_{x}\right.$ and $\left.\underline{B}_{y}\right)$ in a direction normalized by the perpendicular dimension (respectively width: $\underline{b}$ and length: $\underline{L}$ ).

$D 11=\frac{B_{x}}{b}$

$D 22=\frac{B_{y}}{L}$

For a dry tow with minimalistic interactions in the transverse direction between the constituting fibers (mainly introduced by the false twisting during yarn manufacturing) compared to the interactions alongside the fibers in the longitudinal direction. The cohesion in the transversal direction is expected to be much smaller than in the longitudinal direction. This results, for the bending, in $\underline{B}_{x} \gg \underline{B}_{y}$ and with $L>b$ we can safely assume that $D 11 \gg D 22$ and therefore, $D 22$ can be neglected. Furthermore, to the knowledge of the authors, no experimental procedures exists to this day to characterize the transversal bending behavior of a tow and this assumption can not be concluded upon.

$\underline{D 12}$ and $\underline{D 21}$ are equal and represent the bending coupling, which, by Poisson action effect, is the cause of an anticlastic deformation (saddle effect). Considering that the tow is fairly narrow [23] and the beveled sides of the tow [24], it is safe to assume that their effect has a negligible influence on the buckling compared to the other stiffnesses. $\underline{D 66}$, the twisting bending stiffness or torsional stiffness is the torque required to generate a twist $\underline{K_{z}}$ :

$D 66=\frac{G 12 h^{3}}{6}$

With $\underline{G 12}$ being the shear modulus. The critical buckling radius, $\underline{R c r}$, from Eq. (10) can then be written as follows:

$R c r=\frac{E 1(6-\alpha) b^{3} h L^{2}}{\alpha\left(160 D 66 L^{2}+24 D 11 \pi^{2} b^{2} m^{2}\right)}$

This critical buckling radius is expected to correspond to the radius at which the tow buckling appears, but several parameters need to be experimentally evaluated.

\subsection{Parameters identification}

In order to calculate the critical buckling radius, the following parameters $\underline{E 1}, \underline{\alpha}, \underline{D 11}$ and $\underline{D 66}$ need to be identified. The following

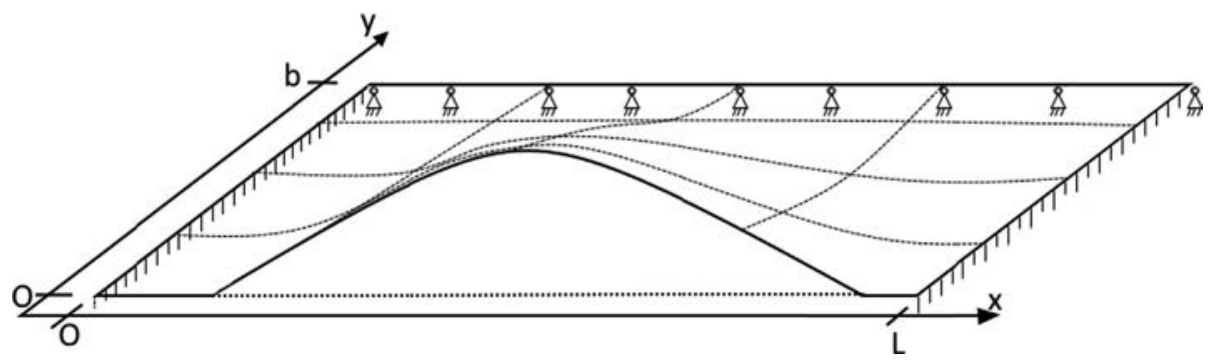

Fig. 15. Boundary condition representation on the buckling portion of the tow. 

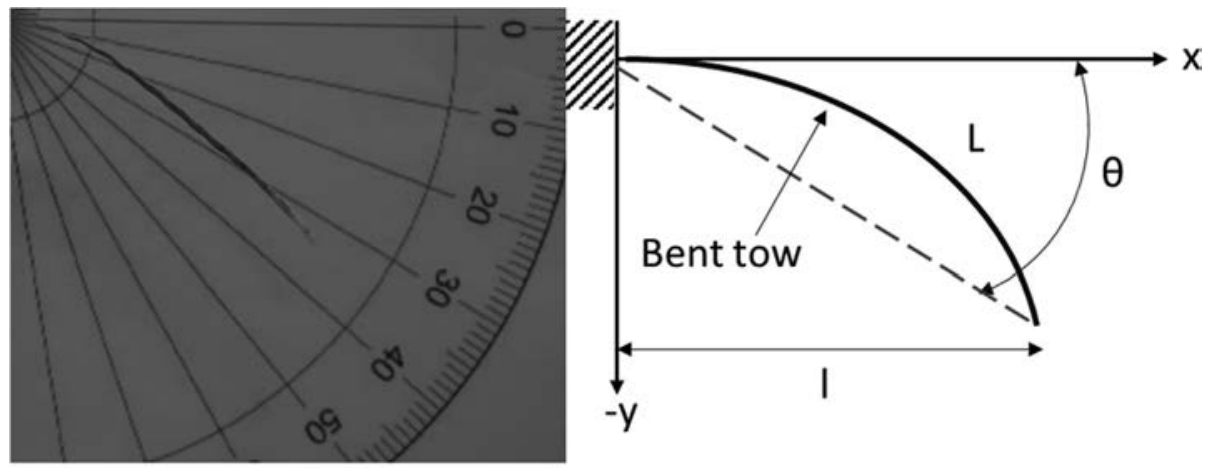

(a)

(b)

Fig. 16. (a) Peirce test on flax tow (b) Schematic representation of Peirce's cantilever test.

sections are dedicated to the experimental identification of the parameters.

\subsubsection{Tensile modulus E1 identification}

The tensile modulus $E 1$, was determined using a tensile test on each of the considered tows. The slope of the linear part of the stress-strain curve was calculated and reported in Table 2.

\subsubsection{Bending stiffness $\underline{D 11}$ identification}

To identify the bending stiffness, $\underline{D 11}$, in Eq. (12), we must determine the bending rigidity, $B_{x}$. It is possible to do so experimentally using the Peirce cantilever test [25] where the tow is bent under its own mass as described in Fig. 14 . The bending rigidity $\underline{B}_{x}$ can calculated using Eq. (16):

$B_{x}=\frac{L^{3} M_{l} g \cos \left(\frac{\theta}{2}\right)}{8 \tan (\theta)}$

where $\underline{L}$ is the bent length of the tow, $M_{l}$ is the linear density, $g$ is the gravity and $\underline{\theta}$ is defined in Fig. 16(b). This means that Eq. (12) can be written with all the parameters that are constant or measurable as shown in Eq. (16):

$D 11=\frac{L^{3} M_{l} g \cos \left(\frac{\theta}{2}\right)}{8 \tan (\theta) b}$

Following the experimental investigation, the results are presented in Table 2 for four different tows taken from different woven fabrics.

\subsubsection{Torsional stiffness D66 identification}

To evaluate $\underline{D 66}$ from Eq. (14), it is necessary to evaluate the inplane shear modulus, $\underline{G 12}$, which is calculated from a torsion test that can be performed on an ARES rheometer as shown in Fig. 17(a) and where the torsional rigidity is given by Eq. (18) [26]:

$\frac{T L}{\varphi}=G 12 J t$

where $\underline{T}$ is the torque, $\underline{L}$ is the length of tow subjected to rotation, $\varphi$ is the torsional angle, $\underline{J}_{t}$ is the polar moment of inertia (similar to second moment of the area for bending) that for a rectangular surface is given by Eq. (19):

$J_{t}=b h^{3}\left(\frac{1}{3}-0.21 \frac{h}{b}\left(1-\frac{h^{4}}{12 b^{4}}\right)\right)$

$T L / \varphi$ can be obtained from a torsion test by averaging the 0 to $2 \pi$ and 0 to $-2 \pi$ slopes of the torque $\underline{T}$ as a function of the unit angle $\varphi / L$ curve as represented in Fig. 17(b). The tow is subjected to an initial tensile loading up to 100 N. Finally, $\underline{D 66}$ from Eqs. (14) and (18) can be written as:
$D 66=\frac{T L h^{3}}{\varphi J t \quad 6}$

The experimental results for the bending stiffness $\underline{D 66}$ are also reported in Table 2.

\subsubsection{Non-uniformity coefficient $\alpha$ identification}

The non-uniformity coefficient was obtained from observation on the tow using digital image correlation using the GOM ARAMIS ${ }^{\circledR}$ software on images such as the one presented in Fig. 18. Zones circled in red are areas representative of tensile loading while zones circled in blue represent compression loading areas. Both areas seem to be fairly equal. The hypothesis of pure bending can be assumed and thus $\underline{\alpha}=2$ was chosen according to the representation given in Fig. 16.

\subsection{Calculation of the critical buckling radius}

The theoretical critical radii were then calculated and compared to the experimental critical radii (tow in plane bending at which buckles appear) in Table 2. As there is no clear definition in the literature for what constitutes the threshold of the buckle's onset, we opted to determine the experimental critical radii by the first sudden increase in the derivative of the tow elevation $d z$ with respect to the bending radius $\underline{R}$ (e.g. dotted line in Fig. 19 for plain weave C), represented in Fig. 19. The aforementioned Figure should be read from highest curvature radius to the lowest (right to left).

The difference between the experimental and the calculated critical radii are given in Table 2 . One can observe that the differences are relatively low with an average error of $8.8 \%$. The fact that the critical radii obtained from the experimental and the analytical approaches are close indicate that the analytical approach permits to predict with a relatively good accuracy (and a global tendency to underestimate) the critical bending radius at which the tow buckles are expected to appear. The observed differences can be due to simplification hypothesis such as the homogeneity assumption of the tow and uncertainties in the radius measurement.

As the analytical model globally permits to predict well the in-plane curvature radius at which the tow buckles are expected to appear, this method could be coupled to a simulation of the textile forming capable to predict the curvature of the tows with a good accuracy. An example of the use of such a combined approach is described in the next section of this work.

\section{Modelling of the defect appearance in a macroscopic simulation}

Once the critical bending radius is determined experimentally or analytically, this result can be of great interest in a macroscopic simulation of the forming process of dry fabrics. Important effort has been paid in the past 20 years in order to predict the mechanical 


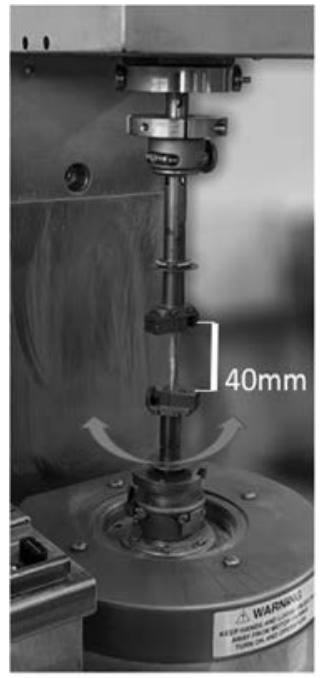

(a)

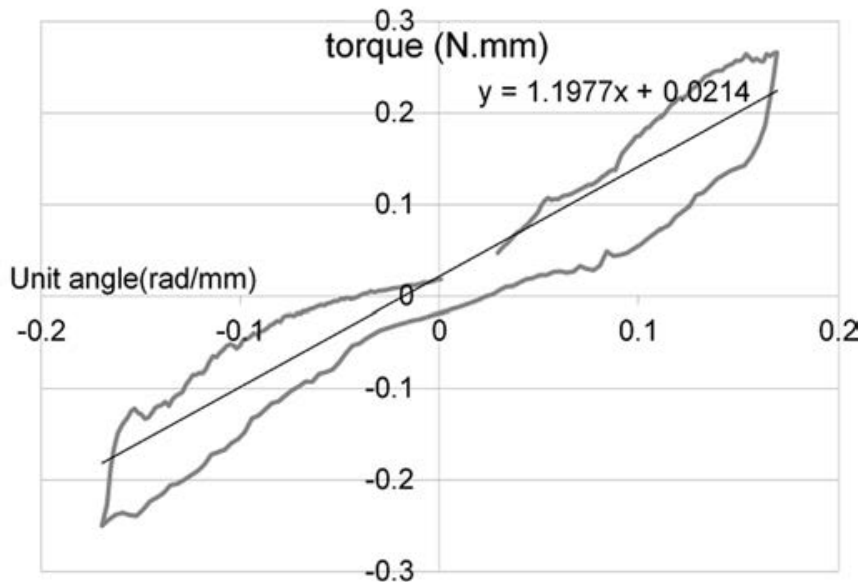

(b)

Fig. 17. (a) Torsion test of ARES rheometer ${ }^{\oplus}$. (b) Torque as a function of unit angle obtained by a torsion test.

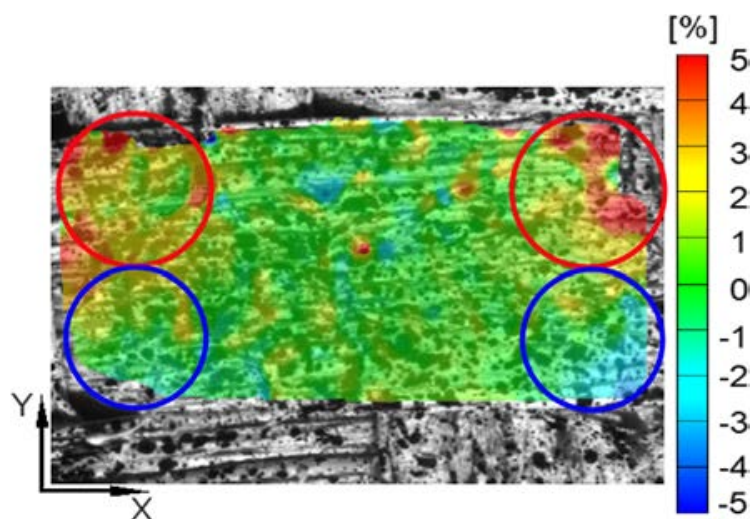

Fig. 18. Digital image correlation of the in-plane deformations of a tow bent in its plane before appearance of tow buckling. (For interpretation of the references to color in this figure legend, the reader is referred to the web version of this article.) response of fabrics during forming at macroscopic scale using numerical simulations. The reached maturity allows now to confidently predict the shear angles via the determination of yarn local orientations. It's then straightforward to use those yarns orientation to evaluate, with a high level of confidence, the curvature of the yarns within a fabric structure during forming. Comparing the local in-plane curvature of the tow (determined during the macroscopic simulation of the textile forming) to the critical one, we can evaluate locally the risk for tow buckling to occur. Several numerical works have been completed in this direction. Gatouillat et al. [15] proposed a fully meso-scale approach using shell elements in order to predict the tow sliding defects and in [19], Iwata et al. investigated macro-scale and meso-scale numerical simulations to predict the buckling of the tows. They finally proposed the use of a hybrid meso/macro-scale approach. The meso/macro-scale simulation takes advantage of macro-scale simulation to determine shear and tensions which in turn are used at meso-scale as boundary conditions in order to predict buckling and tow displacements; mesoscale simulation is only performed in areas where defect are expected to take place. Local curvature is classically evaluated in numerical

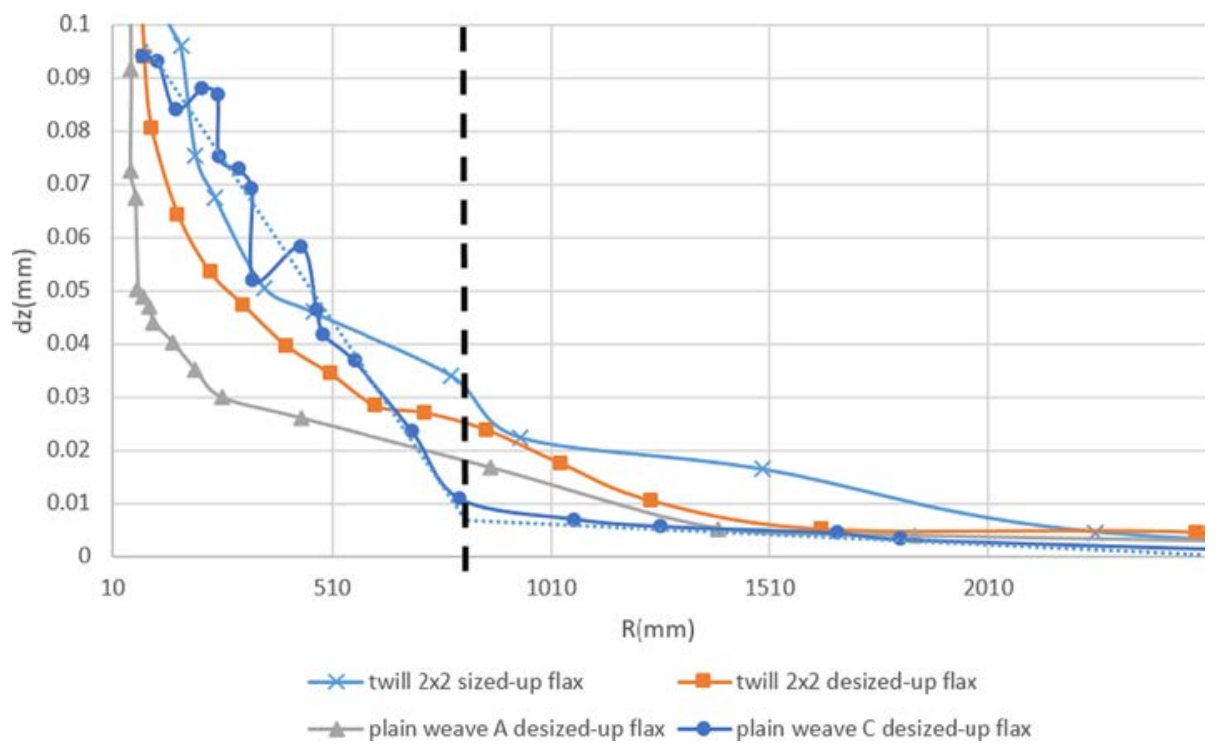

Fig. 19. Tow elevation evolution as a function of the bending radius. (For interpretation of the references to color in this figure legend, the reader is referred to the web version of this article.) 
simulations using neighboring elements $[6,27]$ in order to take into account the bending behavior during a fabric forming. This behavior is proven to be highly influent on the wrinkle's shapes and sizes.

Meso-scale and meso/macro-scale, while being accurate in the prediction of the defect, still require intensive computation resources. Thus, in this work, the use of a macro-scale simulation within an isogeometrical framework [28] is proposed.

Considering a set of rational degree $p$ NURBS shape functions $\underline{R}_{A, p}$. Let us denote $\xi=8(\xi 1, \xi 2, \xi 3)$, the coordinates in the 3 dimensional parametric space of a considered point; its position vector $\mathbf{M}$ at a given time $\underline{t}$ can be obtained considering the control points positions $q_{A}(\mathbf{t})$ and the value of the NURBS shape functions at $\boldsymbol{\xi}$ as shown in Eq. (21).

$\boldsymbol{M}(\xi, t)=\sum_{A} R_{\mathrm{A}, \mathrm{p}}(\xi) \boldsymbol{q}_{A}(t)$

The main advantage of using such a framework comes from the improved continuity of the kinematic approximation that can be built in order to be $\underline{C}^{2}$ everywhere in the domain (even at the frontier between two elements) in order to make the curvature continuous. The mechanical behavior of the fabric is taken into account considering the tensile and in-plane shear contributions of the network separately by computing respectively the corresponding $\mathbf{B}_{\mathrm{B}}$ matrix, $\mathbf{B}_{\mathbf{I}}$ and $\mathbf{B}_{\mathrm{sh}}$ in the same manner as developed in $[29,30]$. A full description of the constitutive model is beyond the scope of this paper.

Tangent vectors $\mathbf{t}_{\mathbf{i}}$ (defied Eq. (22)) are aligned with the material directions of the elements which are chosen to be similar to the fibrous network.

$\boldsymbol{t}_{i}=\frac{\partial \boldsymbol{M}}{\partial \xi_{i}}=\sum_{A} \frac{\partial R_{\mathrm{A}, \mathrm{p}}}{\partial \xi_{i}} \boldsymbol{q}_{A} \quad(\mathrm{i}=1,2)$

Normal vectors $\mathbf{n}_{\mathbf{i}}$ are defined Eq. (23).

$\boldsymbol{n}_{i}=\frac{\partial^{2} \boldsymbol{M}}{\partial \xi_{i}^{2}}=\sum_{A} \frac{\partial^{2} R_{\mathrm{A}, \mathrm{p}}}{\partial \xi_{i}^{2}} \boldsymbol{q}_{A} \quad(\mathrm{i}=1,2)$

Using $\mathbf{t}_{\mathbf{i}}$ and $\mathbf{n}_{\mathbf{i}}$, it is possible to evaluate the curvature of each tow according to Eq. (24):

$C_{i}=\frac{\left\|\boldsymbol{t}_{i} \wedge \boldsymbol{n}_{i}\right\|}{\left\|\boldsymbol{t}_{i}\right\|^{3}}$

$\underline{C}_{i}$ is the total curvature along the $\underline{i}^{\text {th }}$ direction $(\underline{i}=1,2)$, computed from the tangent vector $\mathbf{t}_{\mathbf{i}}$ and the normal vector $\mathbf{n}_{\mathbf{i}}$ which are both obtained from first and second derivatives of the position vector $\mathbf{M}$ with respect to parameter coordinate $\xi_{i}$.

In the tow buckling problem, the in-plane bending, seems from previous investigation, to have the most influence for flat tows; the bending along warp and weft directions are computed following tangent ant normal vectors according to first (warp) and second (weft) directions. We define a unit vector $\mathbf{n}_{\mathbf{1 2}}$ normal to $\left(\mathbf{t}_{1}, \mathbf{t}_{2}\right)$ plane:

$\boldsymbol{n}_{12}=\frac{\boldsymbol{t}_{1} \wedge \boldsymbol{t}_{2}}{\left\|\boldsymbol{t}_{1} \wedge \boldsymbol{t}_{2}\right\|}$

The planar component of those normal vectors $\mathbf{n}_{\mathbf{j}} \mathbf{p l}^{\mathbf{l}}$ (associated to the in-plane curvature) is evaluated:

$\boldsymbol{n}_{i}^{p l}=\boldsymbol{n}_{i}-\boldsymbol{n}_{12}\left(\boldsymbol{n}_{i} \cdot \boldsymbol{n}_{12}\right)$

Finally, the planar curvature $\underline{C_{I}^{p l}}$ along the $\underline{i^{\text {th }}}$ direction is:

$\mathrm{C}_{i}^{p l}=\frac{\left\|\boldsymbol{t}_{i} \wedge \mathrm{n}_{i}^{p l}\right\|}{\left\|\boldsymbol{t}_{i}\right\|^{3}}$

Fig. 20(a) shows that zones of low curvatures can be predicted on the forming simulation of a prismatic shape. The highest in-plane curvatures can be observed on the center and the edges of the triangular face of the prism. The curvatures detected in the red zones of Fig. 20(a) are higher than the curvature level from which tow buckles are expected to appear on the three flax and the carbon fabric tested in this work. These zones do correspond to the buckles locations observed in
Fig. 20(b) for a very different interlock fabric [13].

The zones where tow buckles are expected to appear mainly depend on the shape that induces local curvatures of the tows. However, the magnitude of the tow buckle elevation and the curvature at which the tow buckle may arrive depends on the reinforcement characteristics such as the tow geometry, the tow rigidity and the level of tension of the tows within the shape. The procedure developed in this work therefore permits to indicate according to the fabric characteristics and tension levels in the tows, the zones where tow buckles may take place. It is therefore possible to predict the appearance of tow buckles for a given reinforcement when the constituting tows are experimentally characterized.

\section{Summary and conclusions}

In this research work, we focus on the local buckling (at mesoscopic scale) of flat tows. Subjected to in-plane bending, a longitudinal compression is responsible in some configurations for a local buckling. This defect, leading to poor parts quality, was investigated experimentally and analytically.

Experimentally, a dedicated device capable of imposing tensions and an in-plane bending, combined with stereo digital image correlation was used to evaluate the impact of loading, the impact of the tow behavior and the impact of fabric geometry on the onset and kinematic of the buckle growth.

- We found first that an increased stiffness (in tension and in bending) tends to speedup the buckle phenomenon and to increase the high and rotation of the buckles.

- Also, fabrics with high unsupported length are more sensitive to the buckle defect $(2 \times 2$ twill exhibits more buckles than plain weave for comparable tow width and yarn densities).

- Finally, the experimental study conclusion was that the main driving parameter for the buckling phenomenon was the curvature radius and that tensions impact the buckles through the curvature radius.

Those tendencies were confirmed analytically using a Rayleigh-Ritz approach considering the unsupported portion of a tow in a fabric as an orthotropic plate subjected to bending.

- This approach successfully provide the critical curvature radius for a given fabric constituted of tows of a given nature once the mechanical characteristics of the tows were measured together with the geometrical properties of the fabric.

Results from either the experimental or the analytical approaches can be of valuable interest in a macroscopic simulation of the forming process of a dry fabric. Critical curvature radius can be compared to a simulated one in order to predict the likelihood and location of local buckling defects in a complex part.

- We chose to illustrate this result using an Isogeometrical framework among others for its capability to capture naturally the curvature.

- No additional development is needed and only a post processing is required to gather information regarding the buckle onset in a forming process.

This approach is, of course, very simplified since no tow sliding can be taken into account because of the Lagrange description used for the kinematic. Nevertheless, in classical fabric forming, the sliding defect corresponds to quite extreme scenarios and obtaining a tow buckling criterion in a simulation represents a real gain at low cost. Of course, when tensions in the tows reach certain levels and that tow sliding occurs, meso-scale [11] or smarter multi-scale approaches [19] should be favored. 


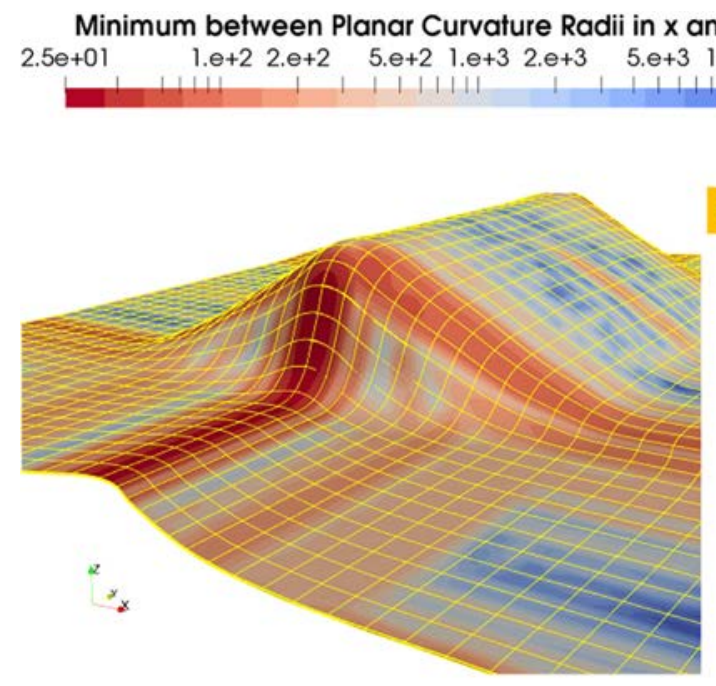

(a)
年 